\title{
Chronic obstructive pulmonary disease classification, phenotypes and risk assessment
}

\author{
Prasad Manian \\ Division of Pulmonary Medicine, Baylor College of Medicine, Houston, TX, USA \\ Correspondence to: Prasad Manian, MD. Baylor College of Medicine, Division of Pulmonary \& Critical Care, 7200 Cambridge, 8A, Houston, TX \\ 77030, USA. Email: pmanian@bcm.edu.
}

\begin{abstract}
Chronic obstructive pulmonary disease (COPD) is a heterogeneous disease. Various classification systems and phenotypes have been proposed. This review highlights the current classifications of COPD, describes the major phenotypes and provides a blue print for risk assessment of COPD. It is likely that more phenotypes and endotypes of COPD will be described paving the way to personalized medicine for patients with COPD.
\end{abstract}

Keywords: COPD classification; COPD phenotype

Submitted Apr 23, 2019. Accepted for publication May 02, 2019.

doi: $10.21037 /$ jtd.2019.05.10

View this article at: http://dx.doi.org/10.21037/jtd.2019.05.10

\section{Chronic obstructive pulmonary disease (COPD) classification}

COPD is defined as "a common, preventable and treatable disease that is characterized by persistent respiratory symptoms and airflow limitation that is due to airway and/or alveolar abnormalities usually caused by significant exposure to noxious particles or gases" (1). The diagnosis of COPD requires the spirometric demonstration of persistent airflow limitation, as defined by post bronchodilator FEV1/FVC $<70 \%$, in patients with appropriate symptoms and history of exposure to noxious stimuli (1). There is considerable heterogeneity in symptoms, disease progression, functional outcomes and response to therapies based on the etiology, pathogenesis and type of lung pathology $(2,3)$ (Figure 1).

Various classification systems for COPD have been developed. The purpose of any classification is to allow categorization of patients in meaningful ways, so as to predict symptoms, functional outcomes, prognosis or response to therapies. The cardinal feature of COPD is airflow limitation. Therefore, the initial classification of COPD by GOLD (Global Initiative for Chronic Obstructive Lung Disease) was based solely on reduction in FEV1 (4). However, there is only a weak correlation between FEV1 and symptom severity, functional status and prognosis (5-8). Dyspnea severity has been shown to better predictor of mortality than FEV1 alone in patients with COPD (9). Subsequently, a multidimensional grading system comprised of dyspnea score, exercise ability, body mass index and FEV1 (BODE Index) was shown to be better than FEV1 alone in predicting respiratory-related as well as all-cause mortality in patients with $\operatorname{COPD}(8,10)$. Further observations revealed that COPD exacerbations were an independent risk factor for mortality in patients with COPD $(11,12)$. The 2011 GOLD guidelines combined FEV1 reduction, dyspnea and exacerbation history into classifying patients with COPD into Groups A-D. This created confusion since patient could qualify for a category based on either FEV1 reduction or exacerbation history (13-15). The more recent GOLD guidelines "grade" COPD severity based on percentage predicted FEV1. Separately, dyspnea severity and exacerbation history are incorporated into a $2 \times 2$ grid to form four "groups" A-D (Figure 2). This GOLD A-D grouping forms the basis for the most recent treatment recommendations $(1,16)$.

\section{COPD phenotypes and endotypes}

It is clear that the COPD GOLD 2018 classification does not capture the heterogeneity of COPD. Different 


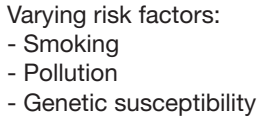

- Smoking

- Genetic susceptibility
Varying pathology:

- Airway abnormalities

- Lung parenchymal destruction

- Systemic effects

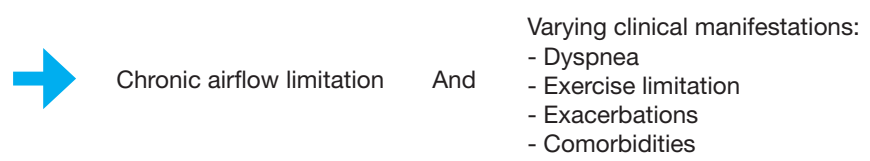

Figure 1 Factors that contribute to the heterogeneity in COPD. COPD, chronic obstructive pulmonary disease.

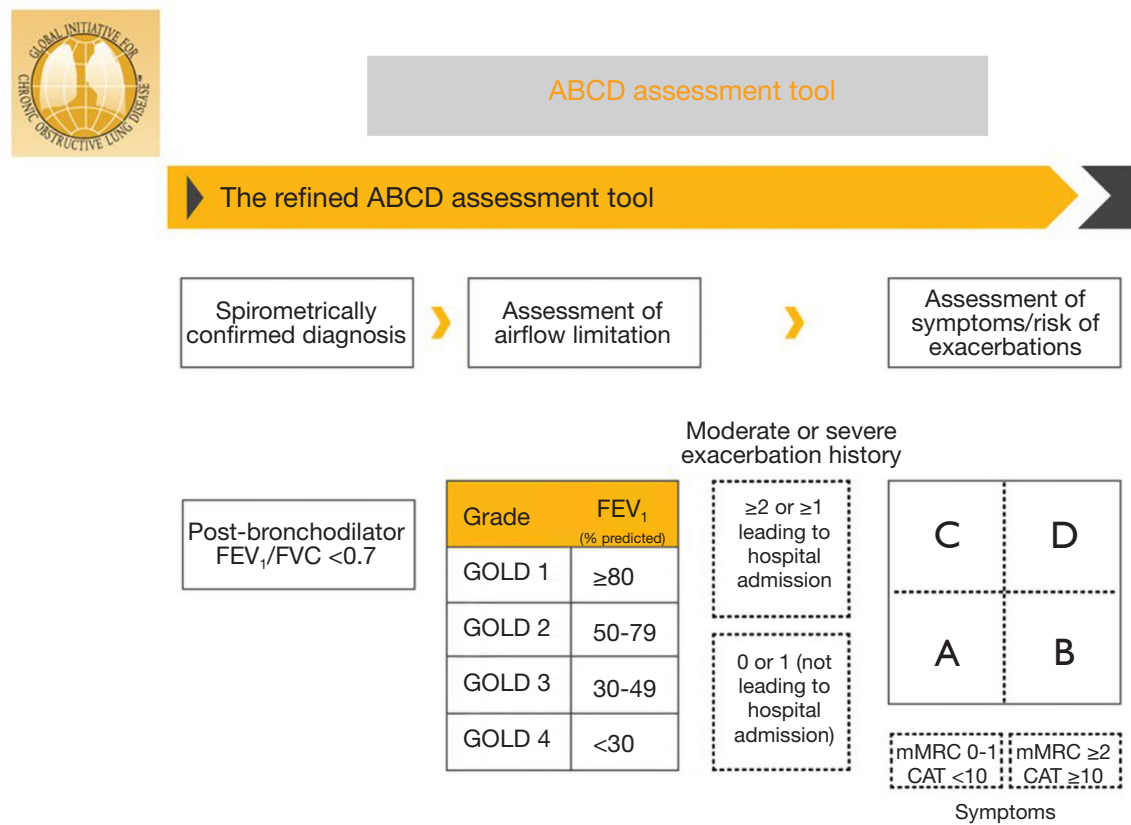

Figure 2 COPD GOLD ABCD Assessment tool (reproduced with permission from Global Initiative for Chronic Obstructive Lung Disease). COPD, chronic obstructive pulmonary disease; GOLD, Global Initiative for Chronic Obstructive Lung Disease.

phenotypes of COPD have been proposed. "Phenotype" refers to a set of observable characteristics with which individuals can be grouped. The purpose of such groupings is to define clusters of patients with common characteristics that relate to clinically meaningful outcomes such as symptoms, prognosis and response to therapies. Phenotypic grouping is essential when researching the pathophysiologic pathways in a disease as heterogeneous as COPD.

The earliest phenotypic classification of COPD separated them into two groups based on physical examination, the "Pink Puffers" and the "Blue Bloaters" (17). As spirometry came into routine use it was recognized that chronic airflow obstruction could be seen in a variety of overlapping conditions, most notably in patients with chronic bronchitis, emphysema and asthma $(18,19)$ (Figure 3). Within this paradigm, the overlap of asthma and COPD and the presence of chronic bronchitis have been proposed as distinct COPD phenotypes.

\section{Asthma-COPD overlap (ACO)}

ACO is a term is used for a phenotype that combines features of both disorders $(20,21)$. ACO is diagnosed when a patient has the defining characteristic of COPD, namely persistent airflow limitation as well as features of asthma (22). It is estimated that between $10-20 \%$ of patients with COPD have features of asthma as well $(22,23)$. ACO is not a single uniform entity but comprises multiple sub-phenotypes, 
such as patients with asthma who have irreversible airway obstruction due to structural changes, patients with asthma and severe disease or asthmatics who smoke and have predominantly neutrophilic inflammation, and patients with COPD and eosinophilic inflammation (23) (Figure 4). Not surprisingly, there are varying definitions of ACO $(24,25)$. ACO patients have not been well studied because they are typically excluded form randomized controlled trials in patients with COPD (22). In general, patients with ACO have more symptoms, more frequent exacerbations, increased risk of hospitalization and a worse quality of life (26-28). On the other hand, patients with ACO appear to have a lower mortality $(21,29)$.

The identification of this subset of patients is important because of the therapeutic implications $(24,30,31)$. Patients with ACO may derive greater benefit from inhaled corticosteroids (ICS), regardless of FEV1 or exacerbation frequency (24). In studies of ICS in COPD, patients with

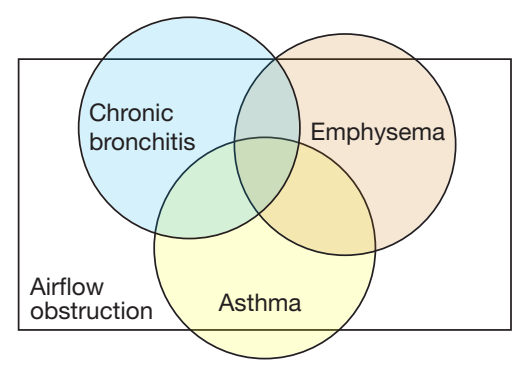

Figure 3 Non-proportional Venn diagram of COPD. COPD, chronic obstructive pulmonary disease.
ACO features had a greater reduction in exacerbation rate (30). Given the variability in the diagnosis of ACOS, some have focused on one easily available biomarker, blood eosinophilia. Blood eosinophilia predicts greater benefit from ICS in patients with COPD, specifically in reduction of exacerbations (32-34). Therapy with mepolizumab, which blocks the interleukin-5 (IL-5) pathway, was associated with a reduction in exacerbations in COPD patients with eosinophilia when compared with placebo (35). On the other hand, a study of benralizumab in patients with COPD and sputum eosinophilia did not reduce the rate of acute exacerbations of COPD (36).

\section{Cbronic bronchitis COPD phenotype}

Individuals with COPD and chronic bronchitis have increased exacerbation frequency, accelerated decline in lung function, worse health-related quality of life and trend to higher mortality as compared with COPD patients without chronic bronchitis $(37,38)$. Among COPD patients with exacerbations, those with chronic bronchitis symptoms, had a higher mortality than those with emphysema (29). This phenotype has therapeutic implications. Roflumilast, an oral phosphodiesterase-4 inhibitor, has been found to be most effective in patients with a chronic bronchitis phenotype and a history of frequent exacerbations $(39,40)$.

\section{Frequent exacerbator COPD phenotype}

COPD exacerbations have been associated with more rapid decline in lung function, worse quality of life and higher

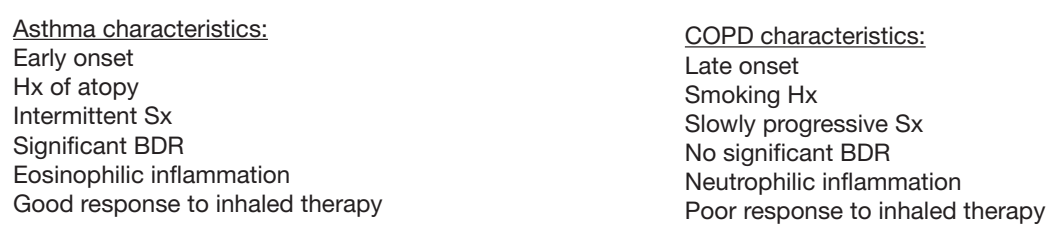

COPD characteristics:
Late onset
Smoking $\mathrm{Hx}$
Slowly progressive Sx
No significant BDR
Neutrophilic inflammation
Poor response to inhaled therapy
Asthma COPD overlap

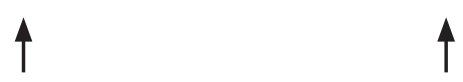

Patients with asthma who have irreversible airway obstruction due to structural changes
Patients with asthma and severe disease or who smoke in whom there is predominantly neutrophilic inflammation

Figure 4 Asthma COPD overlap. COPD, chronic obstructive pulmonary disease. 
Table 1 COPD risk assessment

Spirometry
FEV1/FVC $<70 \%$
FEV1\% predicted
Bronchodilator response
Symptoms
Dyspnea: COPD Assessment Test (CAT) or MRC Dyspnea Scale
Chronic bronchitis
Asthma features
Exacerbation risk
History of prior exacerbations
Blood eosinophilia
Asthma COPD overlap
Blood eosinophilia as biomarker
Identify
Alpha-1-antitrypsin deficiency
Patients with emphysema \& low BMI
Patients with high BMI \& comorbidities
Upper lobe predominant emphysema
COPD, chronic obstructive pulmonary disease; BMI, body mass
index.

healthcare costs (41). Severe COPD exacerbations are associated with a high mortality $(11,42)$. An "Exacerbator" COPD phenotype has been proposed used to identify patients with COPD who are at high risk for exacerbations. The best identifier of the exacerbator phenotype appears to be a history of prior exacerbations $(43,44)$. The frequent exacerbator phenotype is incorporated into the latest COPD GOLD treatment guidelines (1) (Figure 2). The Spanish COPD guidelines (GesEPOC 2017) include the ACOS, chronic bronchitis and exacerbator phenotypes in their treatment algorithm (45).

Other phenotypes have been proposed (46): "Upper lobe-predominant emphysema phenotype" may be considered for lung volume reduction surgery. "Comorbid phenotype" identifies a group of COPD patients that have high BMI, high prevalence of diabetes and heart disease, and higher mortality (46-48). There also appears to be group of patients with emphysema and hyperinflation, and low body mass index who have higher mortality despite having low rates of cardiovascular comorbidities (48).

\section{COPD endotypes}

An endotype is a subtype of a condition, which is defined by a distinct pathobiological mechanism. An example of a COPD endotype would be Alpha-1-antitrypsin (A1AT) deficiency. It is responsible for only a small proportion of patients with COPD, but is important to recognize important given the therapeutic option of A1AT replacement. There is ongoing research into classifying COPD based on the underlying disease mechanisms to guide therapy (49).

\section{Future}

As we continue to refine our understanding of the different disease mechanisms that contribute to COPD ("endotypes"), the future of assessing and managing patients with COPD may extend beyond simple classifications or phenotypic grouping. The future may be in personalized or precision medicine, where we are able to stratify an individual patient based on their phenotype and endotype to tailor their therapy $(50,51)$. But for now, a practical, clinically relevant risk assessment is presented in Table 1 .

\section{Acknowledgments}

None.

\section{Footnote}

Conflicts of Interest: The author has no conflicts of interest to declare.

\section{References}

1. Global Initiative for Chronic Obstructive Lung Disease 2019 [cited 2019 Feb 24]. Available online: www. goldcopd.org

2. Spurzem JR, Rennard SI. Pathogenesis of COPD. Semin Respir Crit Care Med 2005;26:142-53.

3. MacNee W. ABC of chronic obstructive pulmonary disease - Pathology, pathogenesis, and pathophysiology. BMJ 2006;332:1202-4.

4. Pauwels RA, Buist AS, Calverley PM, et al. Global Strategy for the Diagnosis, Management, and Prevention of Chronic Obstructive Pulmonary Disease. Am J Respir Crit Care Med 2001;163:1256-76.

5. Jones P, Miravitlles M, van der Molen T, et al. Beyond 
$\mathrm{FEV}_{1}$ in COPD: a review of patient-reported outcomes and their measurement. Int J Chron Obstruct Pulmon Dis 2012;7:697-709.

6. Gross NJ. Outcome Measures for COPD Treatments: A Critical Evaluation. COPD 2004;1:41-57.

7. Wolkove N, Dajczman E, Colacone A, et al. The relationship between pulmonary function and dyspnea in obstructive lung disease. Chest 1989;96:1247-51.

8. Celli BR, Cote CG, Lareau SC, et al. Predictors of Survival in COPD: More than Just the FEV1. Respir Med 2008;102:S27-35.

9. Nishimura K, Izumi T, Tsukino M, et al. Dyspnea is a better predictor of 5 -year survival than airway obstruction in patients with COPD. Chest 2002;121:1434-40.

10. Celli BR, Cote CG, Marin JM, et al. The Body-Mass Index, Airflow Obstruction, Dyspnea, and Exercise Capacity Index in Chronic Obstructive Pulmonary Disease. N Engl J Med 2004;350:1005-12.

11. Soler-Cataluña JJ, Martínez-García MA, Román Sánchez P, et al. Severe acute exacerbations and mortality in patients with chronic obstructive pulmonary disease. Thorax 2005;60:925-31.

12. Schmidt SAJ, Johansen MB, Olsen M, et al. The impact of exacerbation frequency on mortality following acute exacerbations of COPD: a registry-based cohort study. BMJ Open 2014;4:e006720.

13. Han MK, Muellerova H, Curran-Everett D, et al. GOLD 2011 disease severity classification in COPDGene: a prospective cohort study. Lancet Respir Med 2013;1:43-50.

14. Yusen RD. Evolution of the GOLD Documents for the Diagnosis, Management, and Prevention of Chronic Obstructive Pulmonary Disease. Controversies and Questions. Am J Respir Crit Care Med 2013;188:4-5.

15. Agusti A, Hurd S, Jones P, et al. FAQs about the GOLD 2011 assessment proposal of COPD: a comparative analysis of four different cohorts. Eur Respir J 2013;42:1391-401.

16. Mirza S, Clay RD, Koslow MA, et al. COPD Guidelines: A Review of the 2018 GOLD Report. Mayo Clin Proc 2018;93:1488-502.

17. Dornhorst AC. Respiratory insufficiency. Lancet 1955;268:1185-7.

18. Snider GL. Chronic Obstructive Pulmonary Disease: A Definition and Implications of Structural Determinants of Airflow Obstruction for Epidemiology. Am Rev Respir Dis 1989;140:S3-8.

19. Standards for the diagnosis and care of patients with chronic obstructive pulmonary disease. American Thoracic
Society. Am J Respir Crit Care Med 1995;152:S77-121.

20. Barrecheguren M, Esquinas C, Miravitlles M. The asthmachronic obstructive pulmonary disease overlap syndrome (ACOS). Curr Opin Pulm Med 2015;21:74-9.

21. Cosio BG, Soriano JB, López-Campos JL, et al. Defining the Asthma-COPD Overlap Syndrome in a COPD Cohort. Chest 2016;149:45-52.

22. Gibson PG, McDonald VM. Asthma-COPD overlap 2015: now we are six. Thorax 2015;70:683-91.

23. Barnes PJ. Asthma-COPD Overlap. Chest 2016;149:7-8.

24. Bujarski S, Parulekar AD, Sharafkhaneh A, et al. The Asthma COPD Overlap Syndrome (ACOS). Curr Allergy Asthma Rep 2015;15:509.

25. Woodruff PG, van den Berge M, Boucher RC, et al. American Thoracic Society/National Heart, Lung, and Blood Institute Asthma-Chronic Obstructive Pulmonary Disease Overlap Workshop Report. Am J Respir Crit Care Med 2017;196:375-81.

26. Menezes AMB, Montes de Oca M, Pérez-Padilla R, et al. Increased Risk of Exacerbation and Hospitalization in Subjects With an Overlap Phenotype. Chest 2014;145:297-304.

27. Andersén H, Lampela P, Nevanlinna A, et al. High hospital burden in overlap syndrome of asthma and COPD. Clin Respir J 2013;7:342-6.

28. Kauppi P, Kupiainen H, Lindqvist A, et al. Overlap Syndrome of Asthma and COPD Predicts Low Quality of Life. J Asthma 2011;48:279-85.

29. Hernández Vázquez J, Ali García I, Jiménez-García R, et al. COPD phenotypes: differences in survival. Int J Chron Obstruct Pulmon Dis 2018;13:2245-51.

30. Cosío BG, Dacal D, Pérez de Llano L. Asthma-COPD overlap: identification and optimal treatment. Ther Adv Respir Dis 2018;12:1753466618805662.

31. Barnes PJ. Therapeutic approaches to asthma-chronic obstructive pulmonary disease overlap syndromes. J Allergy Clin Immunol 2015;136:531-45.

32. Pascoe S, Locantore N, Dransfield MT, et al. Blood eosinophil counts, exacerbations, and response to the addition of inhaled fluticasone furoate to vilanterol in patients with chronic obstructive pulmonary disease: a secondary analysis of data from two parallel randomised controlled trials. Lancet Respir Med 2015;3:435-42.

33. Yilmaz I, Turk M. What Should Be the Cutoff Value of Blood Eosinophilia as a Predictor of Inhaled Corticosteroid Responsiveness in Patients with Chronic Obstructive Pulmonary Disease? Am J Respir Crit Care Med 2017;196:1229-30. 
34. Lipson DA, Barnhart F, Brealey N, et al. Once-Daily Single-Inhaler Triple versus Dual Therapy in Patients with COPD. N Engl J Med 2018;378:1671-80.

35. Pavord ID, Chanez P, Criner GJ, et al. Mepolizumab for Eosinophilic Chronic Obstructive Pulmonary Disease. N Engl J Med 2017;377:1613-29.

36. Brightling CE, Bleecker ER, Panettieri RA, et al. Benralizumab for chronic obstructive pulmonary disease and sputum eosinophilia: a randomised, double-blind, placebo-controlled, phase 2a study. Lancet Respir Med 2014;2:891-901.

37. Burgel PR, Nesme-Meyer P, Chanez P, et al. Cough and Sputum Production Are Associated With Frequent Exacerbations and Hospitalizations in COPD Subjects. Chest 2009; 135:975-82.

38. Kim V, Han MK, Vance GB, et al. The chronic bronchitic phenotype of COPD: an analysis of the COPDGene Study. Chest 2011;140:626-33.

39. Calverley PM, Rabe KF, Goehring UM, et al. Roflumilast in symptomatic chronic obstructive pulmonary disease: two randomised clinical trials. Lancet 2009;374:685-94.

40. Rennard SI, Calverley PM, Goehring UM, et al. Reduction of exacerbations by the PDE4 inhibitor roflumilast - the importance of defining different subsets of patients with COPD. Respir Res 2011;12:18.

41. Anzueto A. Impact of exacerbations on COPD. Eur Respir Rev 2010;19:113-8.

42. Connors AF, Dawson N V, Thomas C, et al. Outcomes following acute exacerbation of severe chronic obstructive lung disease. The SUPPORT investigators (Study to Understand Prognoses and Preferences for Outcomes and Risks of Treatments). Am J Respir Crit Care Med

Cite this article as: Manian P. Chronic obstructive pulmonary disease classification, phenotypes and risk assessment. J Thorac Dis 2019;11(Suppl 14):S1761-S1766. doi: 10.21037/jtd.2019.05.10
1996;154:959-67.

43. Hurst JR, Vestbo J, Anzueto A, et al. Susceptibility to Exacerbation in Chronic Obstructive Pulmonary Disease. N Engl J Med 2010;363:1128-38.

44. Le Rouzic O, Roche N, Cortot AB, et al. Defining the "Frequent Exacerbator" Phenotype in COPD: A Hypothesis-Free Approach. Chest 2018;153:1106-15.

45. Miravitlles M, Soler-Cataluña JJ, Calle M, et al. Spanish COPD Guidelines (GesEPOC) 2017. Pharmacological Treatment of Stable Chronic Obstructive Pulmonary Disease. Arch Bronconeumol 2017;53:324-35.

46. Mirza S, Benzo R. Chronic Obstructive Pulmonary Disease Phenotypes: Implications for Care. Mayo Clin Proc 2017;92:1104-12.

47. Pinto LM, Alghamdi M, Benedetti A, et al. Derivation and validation of clinical phenotypes for COPD: a systematic review. Respir Res 2015;16:50.

48. Burgel PR, Paillasseur JL, Peene B, et al. Two distinct chronic obstructive pulmonary disease (COPD) phenotypes are associated with high risk of mortality. PLoS One 2012;7:e51048.

49. Agustí A, Celli B, Faner R. What does endotyping mean for treatment in chronic obstructive pulmonary disease? Lancet 2017;390:980-7.

50. Sidhaye VK, Nishida K, Martinez FJ. Precision medicine in COPD: where are we and where do we need to go? Eur Respir Rev 2018;27:180022.

51. Lee JS, Lee SD. Personalized Treatment in COPD. In: COPD [Internet]. Berlin, Heidelberg: Springer Berlin Heidelberg, 2017:299-310. Available online: http://link. springer.com/10.1007/978-3-662-47178-4_20 